\title{
Guidance Molecules in Axon Pruning and Cell Death
}

\author{
Pierre Vanderhaeghen ${ }^{1}$ and Hwai-Jong Cheng ${ }^{2}$ \\ ${ }^{1}$ Université Libre de Bruxelles (ULB), IRIBHM, Brussels, Belgium \\ ${ }^{2}$ University of California, Davis, Center for Neuroscience, Davis, California 95618 \\ Correspondence: pierre.vanderhaeghen@ulb.ac.be and hjcheng@ucdavis.edu
}

\begin{abstract}
Axon pruning and neuronal cell death constitute two major regressive events that enable the establishment of fully mature brain architecture and connectivity. Although the cellular mechanisms for these two events are thought to be distinct, recent evidence has indicated the direct involvement of axon guidance molecules, including semaphorins, netrins, and ephrins, in controlling both processes. Here, we review how axon guidance cues regulate regressive events in paradigmatic models of neural development, from early control of apoptosis of neural progenitors, to later maintenance of neuronal survival and stereotyped pruning of axonal branches. These new findings are also discussed in the context of neural diseases and the potential links between axon pruning and degeneration.
\end{abstract}

\section{REGRESSIVE EVENTS IN NEURONAL DEVELOPMENT}

$T_{\mathrm{i} \text { he }}^{\mathrm{h}}$ he development of the nervous system involves progressive and regressive events (Cowan et al. 1984; Low and Cheng 2006). Progressive events like neural proliferation, neurite outgrowth, and synapse formation set up a broad pattern of neural connectivity. Later in development, however, regressive events such as cell death, axon pruning, and synapse elimination are necessary to refine the pattern to a more precise and mature circuitry. Some of the regressive events are crucial for proper brain development and function. Mutations in the apoptotic pathway can lead to gross morphological defects of the brain that result in lethality (Cecconi et al. 1998; Kuida et al. 1998; Kuida et al.
1996; Yoshida et al. 1998). At later stages, disruption of neuronal death and/or axon pruning can perturb the neuronal network and lead to brain dysfunction (Johnston 2004; Lewis and Levitt 2002; Pardo and Eberhart 2007).

Axon pruning and neuronal cell death are thought to be controlled by largely distinct cellular mechanisms (Bredesen et al. 2006; Buss et al. 2006; Buss and Oppenheim, 2004; Low and Cheng, 2006). Axon pruning enables removal of exuberant or misguided axon branches in the absence of cell death, whereas other appropriate connections of the same neuron are maintained. In contrast, cell death removes the entire neuron and ultimately leads to the loss of all neurites associated with the dying parent neuron.

Editors: Marc Tessier-Lavigne and Alex L. Kolodkin

Additional Perspectives on Neuronal Guidance available at www.cshperspectives.org

Copyright (C) 2010 Cold Spring Harbor Laboratory Press; all rights reserved; doi: 10.1101/cshperspect.a001859

Cite this article as Cold Spring Harb Perspect Biol 2010;2:a001859 
The elimination of axon branches can occur at different levels, either involving small-scale pruning of axon terminals (Fig. 1A), or a larger-scale removal of inappropriate collateral branches (Fig. 1B). Despite the differences, it seems that in all pruning events, synapses are commonly formed by transient axonal terminals or branches such that synapse elimination often goes along with axon pruning.

Neuronal cell death takes place at several stages of neural development (see Fig. 4). During vertebrate brain development, about $50 \%$ of the neurons do not survive into adulthood, most of which die by programmed cell death (PCD), resulting in the loss of the cell and all its synapses and processes (Cowan 2001; Cowan et al. 1984; Yuan et al. 2003). More recent evidence points to additional roles of PCD at earlier stages of neural development, including at the level of differentiating immature neurons

A Small-scale axon terminal pruning

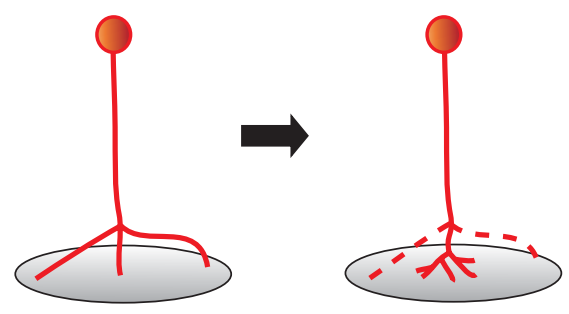

B Large-scale stereotyped axon pruning

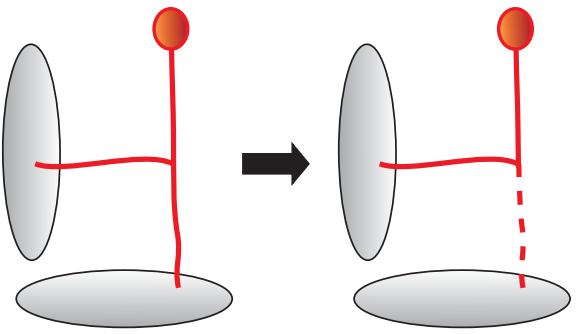

Figure 1. Two variations of axon pruning. (A) In small-scale axon terminal pruning, the axon first extends short axon terminal arbors toward cells within the same target area. Later, some of the terminal arbors are randomly pruned through competition. (B) In large-scale stereotyped axon pruning, the neuron first sends long axon collateral branches to multiple appropriate and inappropriate target areas. Later, the branches to the inappropriate target areas are predictably pruned away. and dividing neural progenitors (Haydar et al. 1999; Kuan et al. 2000).

\section{"REGRESSIVE EVENTS" IN DISEASES}

Axon pruning and neuronal cell death also occur when the nervous system is injured or degenerates (Coleman 2005; Low and Cheng 2006; Luo and O'Leary 2005; Raff et al. 2002). In Wallerian degeneration, which occurs after axons are severed, the distal portion of the axon degrades quickly, whereas the neuron itself can often survive and the proximal portion of the axon eventually regrows. In contrast, in many neurodegenerative diseases, the axon gradually degrades over time and the neuron dies in the end. This "dying back" mechanism is distinct from Wallerian degeneration. Dying back usually takes place over a much slower time course than Wallerian degeneration, and occurs in a distal to proximal fashion. During neurodegenerative diseases, axon degeneration seems to lead invariably to neuronal cell death.

Axon pruning and Wallerian degeneration have been studied extensively in mouse and Drosophila, and several intrinsic and extrinsic factors have been identified in these processes (Coleman 2005; Low and Cheng 2006). Classical studies on neural cell death have also led to the discovery of neurotrophic factors and neuro-apoptotic pathways (Buss et al. 2006; Cowan 2001; Oppenheim et al. 2001). More recent studies have uncovered the roles of axon guidance molecules in neuronal cell death and axon pruning, so far mostly limited to the developmental events. Here, we focus on classical models of axon pruning and PCD in developing vertebrates, and discuss the role of axon guidance molecules in these events.

\section{AXON PRUNING: THE MODELS}

\section{Small-scale Axon Terminal Arbor Pruning}

Small-scale axon pruning occurs stochastically and may be regulated by neural activity. Classical vertebrate examples of small-scale axon terminal arbor pruning include the pruning of the axon terminals in the neuromuscular junction 
(NMJ) in the peripheral nervous system (PNS) (Fig. 2A-1) and the pruning of climbing fiber inputs to the cerebellum in the central nervous system (CNS) (Fig. 2A-2). The NMJ develops from a broad pattern of polyinnervation by muscle fibers to a refined monoinnervation pattern where fibers are connected by a single terminal arbor from a single motor axon (Lichtman and Colman 2000; Luo and O'Leary 2005; Sanes and Lichtman 2001). Terminal arbors are removed by axon and synapse elimination, rather than by cell death (Riley 1981; Lichtman and Colman 2000; Sanes and Lichtman 1999). Recent data indicate that these arbors are pruned by axosome shedding (Bishop et al. 2004), which is associated with lysosomal activities (Song et al. 2008). The pruning of the climbing fibers also involves elimination of competing arbors and synapses (Hashimoto and Kano 2003; Hashimoto et al. 2009; Lohof et al. 1996; Mason and Gregory 1984). Interestingly, climbing fiber synapse elimination is associated with structures resembling axosomes (Eckenhoff and Pysh 1979), suggesting that small-scale terminal arbor pruning might operate along similar cellular mechanisms in the PNS and the CNS (Hashimoto et al. 2009).

Large-scale Stereotyped Axon Pruning

\section{Stereotyped Pruning in the Cerebral Cortex}

Large-scale stereotyped pruning was first shown in the remodeling of cortical callosal axon branches that project to the contralateral side of the brain (Innocenti 1981; Innocenti and Clarke 1984; Innocenti and Price 2005) (Fig. 2B-1). This pruning seems to rely on normal input, as altering visual activity feeding into the projecting neurons leads to profound pruning defects (Dehay et al. 1989; Innocenti and Price 2005; Koralek and Killackey 1990; Shatz 1977). Another well-studied example of large-scale stereotyped pruning in the cerebral cortex is the refinement of subcortical projections arising from the visual and motor cortices (O’Leary et al. 1990; O'Leary and Koester 1993; Stanfield 1992; Stanfield et al. 1982) (Fig. 2B-2). Axons originating from neurons of these two cortices are guided initially to subcortical targets that overlap in the brain stem and spinal cord. Later in development, only the collateral branches that are functionally appropriate for each cortical region are retained. Thus, neurons from the visual cortex prune away their branches that extend to motor system targets. In contrast, neurons from the motor cortex prune their branches that extend to the visual superior colliculus. The axon collaterals are removed within the first few weeks of postnatal development. Previous tracing studies reported the presence of fragmented axons, suggesting a degeneration mechanism for the pruning (Reinoso and O'Leary 1989), but this still needs to be confirmed by ultrastructural analyses. There is still no evidence indicating whether this stereotyped pruning is regulated by neural activity.

\section{Stereotyped Pruning in the Hippocampus}

The hippocampus is another area in the CNS in which considerable remodeling of projections occurs (Bagri et al. 2003). In the hippocamposeptal pruning the pyramidal cells in CA1 send axons to the medial septum at late prenatal stages. After these axons sprout collateral branches to the lateral septum, they prune away the original projections to the medial septum, leaving the hippocampo-septal connection from CA1 only to the lateral septum. Another well-studied stereotyped axon pruning event in the hippocampus is the infrapyramidal bundle (IPB) pruning (Fig. 2B-3) (Bagri et al. 2003). During development, granule cells of the dentate gyrus extend two bundles of mossy fiber axons to CA3: a main bundle that courses adjacent to the apical dendrites of CA3 pyramidal cells, and a transient IPB of axon collaterals that course adjacent to the basal dendrites of the pyramidal cells (Amaral and Dent 1981; Bagri et al. 2003). The transient long IPB is stereotypically pruned back later in development. Electron microscopic analysis suggests that the IPB pruning is mediated by axon branch retraction (Liu et al. 2005), and the length of the IPB is reported to be affected 
P. Vanderhaeghen and H.-J. Cheng

A Small-scale axon terminal pruning

A-1 Muscle cell

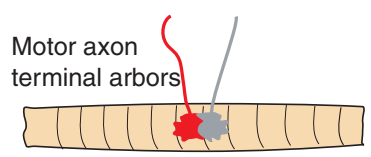

1

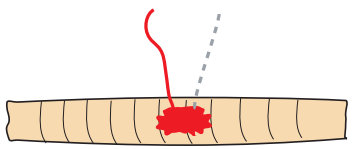

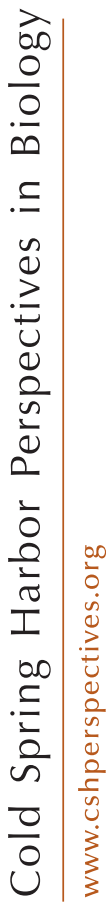

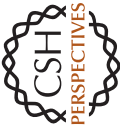

B-1

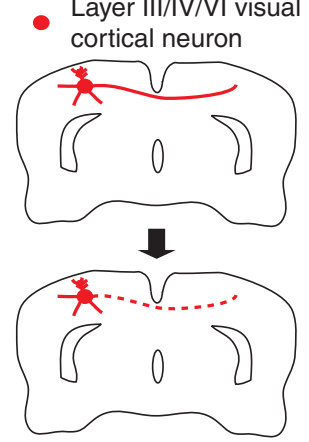

B-3

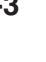

Hippocampal dentate granule cell

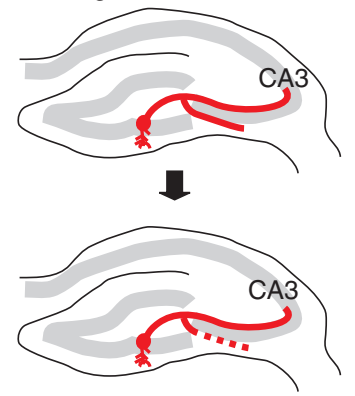

A-2 Purkinje cell

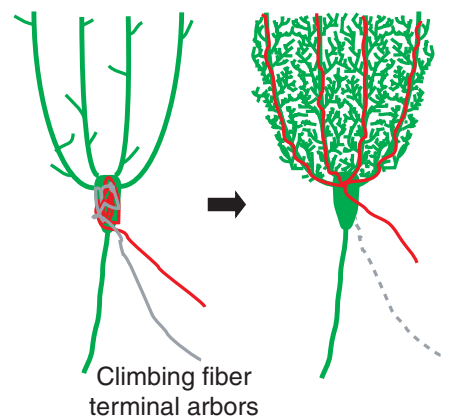

terminal arbors

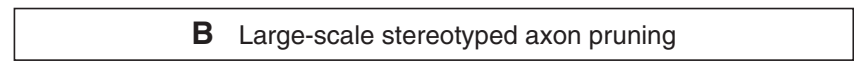

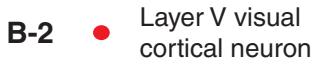
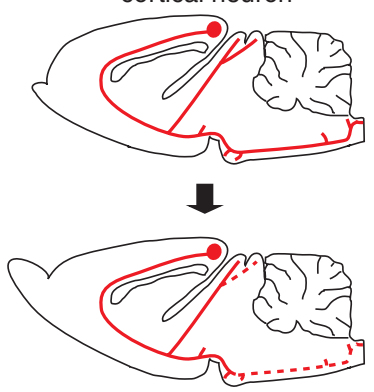

B-4 Retinal ganglion

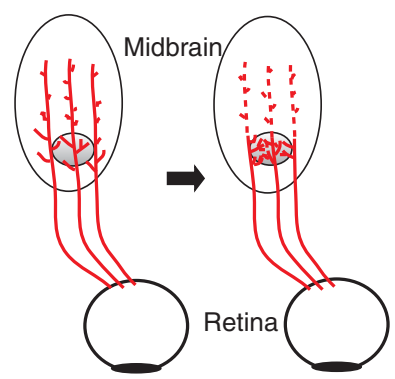

Figure 2. Classical examples of developmental axon pruning in vertebrates. (A) Small-scale axon terminal pruning. In the pruning of the developing neuromuscular junction $(A-1)$, multiple short axon terminal arbors compete for one muscle fiber, but only one arbor eventually stays. In the pruning of the climbing fiber terminals in the cerebellum $(A-2)$, the cell body of a Purkinje cell is initially innervated by multiple climbing fiber terminal arbors, but later only one terminal arbor can climb up the dendrites of the Purkinje cell. All other terminal arbors are pruned. $(B)$ Large-scale stereotyped axon pruning. In the pruning of the cortical callosal projections $(B-1)$, long projections from layer III/IV/VI visual cortical neurons to the contralateral cortex are pruned. In the pruning of corticospinal projections $(B-2)$, long projections from layer $\mathrm{V}$ visual cortical neurons to multiple subcortical target regions are pruned. In the pruning of hippocampal mossy fibers $(B-3)$, the infrapyramidal branches of the mossy fibers from the dentate granule cells to the CA3 region are pruned. Finally, in the formation of the retinotopic map $(B-4)$, the overextended retinal axons that pass their terminal zone in the midbrain are pruned. 
by relative levels of activity in the hippocampus (Adams et al. 1997).

\section{Stereotyped Axon Pruning in the Topographic Mapping of Retinal Projections}

In the adult nervous system, most areas of the brain contain connections that are organized in a functional pattern called a topographic map. The best-studied example is the retinotopic connections of the retinal ganglion cell (RGC) axons to the midbrain (Fig. 2B-4) (Flanagan 2006; Luo and Flanagan 2007; McLaughlin and O'Leary 2005). In early development of the chicken and rodent visual system, the axonal projection map is less refined as RGCs overextend their axons beyond their intended targets. This is followed by interstitial branching of axon collaterals to the proper terminal zone. The cellular mechanism of this pruning has not been elucidated; however, axon tracing studies have revealed an increase in the blebbing of axonal processes, which is reminiscent of axonal degeneration (Nakamura and O'Leary 1989). After stereotyped pruning of overextended axon branches, the retinotopic map is still not completely refined. Normal patterns of visual activity are required to further refine the broad distribution of secondary and tertiary arbors that branch off from the axon terminals (McLaughlin and O’Leary 2005).

\section{GUIDANCE MOLECULES IN AXON PRUNING}

\section{Intrinsic and Extrinsic Factors}

It is likely that the molecular mechanisms for each pruning event are quite diverse. In principle, axon pruning can be initiated by intrinsic degeneration or a retraction program because of maturation or differentiation of the neuron. Alternatively, pruning can be triggered by extrinsic factors from the environment. In the past decade, studies from model organisms have identified intrinsic and extrinsic factors that can regulate pruning processes. For example, many axons and dendrites in Drosophila at larval stages are extensively pruned during metamorphosis (Truman 1990). Ecdysone is a major extrinsic factor that triggers metamorphosis: It is conceivable that an ecdysone receptor and a homolog of mammalian retinoic acid receptor are required cell-autonomously for the pruning (Lee et al. 2000; Luo and O'Leary 2005). However, not all pruning events in Drosophila are associated with hormones and axon degeneration. At the Drosophila NMJ, a rapid disassembly of synapses and the retraction of axonal arbors occur concurrently with a proliferative phase of synaptic growth (Eaton et al. 2002; Hebbar and Fernandes 2004).

Various intrinsic factors have been identified to regulate the pruning of axons and dendrites in Drosophila. These include the ubiquitin-proteosome system (Kuo et al. 2006; Watts et al. 2003), regulators of cytoskeletal dynamics (Billuart et al. 2001; Lee et al. 2009), caspase activities (Williams et al. 2006), transcription factors (Parrish et al. 2007), RNAbinding proteins (Hoopfer et al. 2008), proteins that hold sister chromatids together (Schuldiner et al. 2008), and the FMRP protein disrupted in fragile $\mathrm{X}$ mental retardation (Tessier and Broadie 2008). Notably, molecular mechanisms involved in axon pruning in Drosophila share similarities with Wallerian degeneration in vertebrates. Wallerian degeneration is thought to be mediated by an intrinsic mechanism of axon self-destruction (Avery et al. 2009; Coleman et al. 1998; Conforti et al. 2000; Lunn et al. 1989; Mack et al. 2001), which also involves the ubiquitin-proteosome system (Watts et al. 2003; Zhai et al. 2003).

Metamorphosis in Drosophila is a mass remodeling of the entire nervous system, which happens globally and simultaneously (Truman 1990). This is in contrast to axon pruning in the mammalian nervous system that occurs locally and at multiple developmental stages (O'Leary and Koester 1993). The fact that Drosophila pruning is similar to vertebrate Wallerian degeneration, a pathological but not developmental process, might suggest that axon pruning in Drosophila is different from developmental stereotyped axon pruning in vertebrates. Indeed, the large-scale pruning events are 
preserved in mice defective in Wallerian degeneration (Hoopfer et al. 2006).

Different groups of intrinsic and extrinsic factors have been identified in regulating developmental axon pruning in vertebrates. Although neural activity is thought to play important roles in small-scale axon arbor pruning, the molecular factors that mediate this type of pruning are largely unknown. In contrast, some molecular factors have been shown to play roles in large-scale stereotyped pruning. As for intrinsic factors, a homeodomain transcription factor Otxl has been found to regulate the CST pruning of the visual cortex, although the underlying mechanisms remain unclear (Weimann et al. 1999). Hormones and trophic factors have traditionally been thought to be the major extrinsic factors to regulate large-scale stereotyped axon pruning in vertebrates (Cowan et al. 1984; Innocenti and Price 2005; Singh et al. 2008), but similarly to ecdysone in Drosophila, their effects are often broad and nonspecific. Recently, axon repulsion molecules have been recognized as an important group of extrinsic factors in regulating stereotyped axon pruning.

\section{Semaphorin, Neuropilin, and Plexin}

Semaphorin ligands and their receptors, neuropilins and plexins, have been implicated in large-scale stereotyped pruning processes in the central nervous system (Bagri et al. 2003). The hippocampo-septal pruning is defective in the plexin-A3 mutants. Sema3A is expressed in the relevant target at the time of pruning, suggesting that Sema3A, through plexin-A3, regulates the hippocampo-septal pruning. During the stereotyped pruning of the IPB, granule cells express plexin-A3, plexin-A4, and neuropilin-2, and Sema $3 \mathrm{~F}$ is expressed in a spatially restricted manner along the areas coursed by the IPB projections. Disruption of any of these genes in the mouse results in profound pruning defects in the IPB (Bagri et al. 2003; Faulkner et al. 2007; Sahay et al. 2003), indicating that this signaling pathway regulates the IPB pruning.

Recent data also indicate that Sema3F signaling through neuropilin-2, plexin-A3, and plexin-A4 are differentially required for the stereotyped pruning of the corticospinal tract (Low et al. 2008). Plexin-A3, plexin-A4, and neuropilin-2 are specifically expressed in the visual, but not motor cortex at the time when visual CST axon branches are stereotypically pruned. Mutant analysis shows that the visual CST pruning is defective in either neuropilin-2 mutants or plexin-A 3 and plexin-A4 double mutants. However, no motor CST pruning defect can be detected in these mutants. Sema3F is strongly expressed in the dorsal spinal cord at the time of pruning. Thus, Sema3F signaling is required for the pruning of the visual CST.

Quantitative immuno-electron microscopy has shown that the IPB axons form transient synaptic contacts in their transient target region before they are pruned (Liu et al. 2005). The pruning of the IPB is preceded by the elimination of these immature synaptic contacts, which is triggered by the action of Sema3F signaling. Interestingly, the transient visual CST axons also form synaptic contacts with neurons in the spinal gray matter, suggesting that many of the transient branches in the CNS form synaptic contacts before pruning (Low et al. 2008).

How can axon repellents such as semaphorins also regulate synapse elimination and axon pruning? One of the main signaling effects of axon repellents is to induce local or global cytoskeletal rearrangement in axons. Thus, axon repulsion, synapse elimination, and axon pruning may all be mediated through changing cytoskeletal dynamics, and the differences seem to lie in the timing of the signaling and the scale of these effects (Fig. 3) (Waimey and Cheng 2006). Take semaphorin signaling as an example: In axon repulsion, growing axons that already express plexins on their growth cones turn away from pre-existing semaphorin gradients before they can reach the tissues that secrete semaphorins (Fig. 3A). In axon pruning, however, axons first grow into a transient target region in the absence of semaphorin signaling. This may be because of the absence of semaphorin expression by the target, a lack of plexin expression on growth cones, or both. Later, activated semaphorin signaling triggers the pruning of axon branches that have grown into this area (Fig. 3B). Finally, the removal of synapses 
Pruning and Death

\begin{abstract}
A Axon repulsion
\end{abstract}
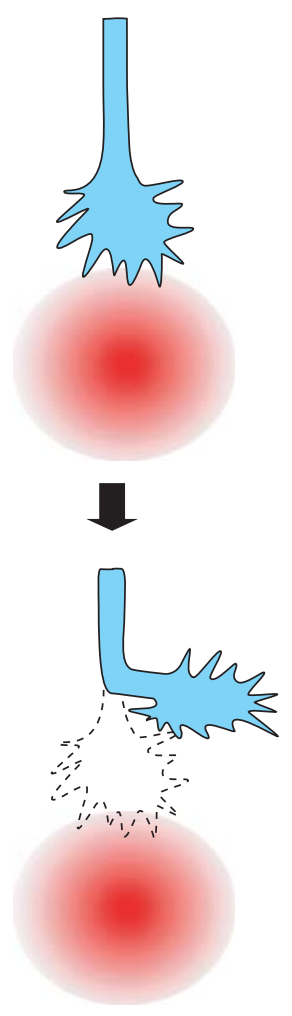

B Axon pruning
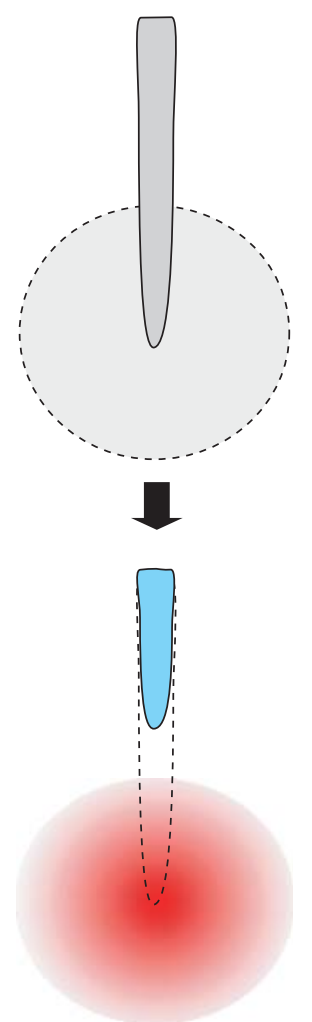

C Synapse elimination
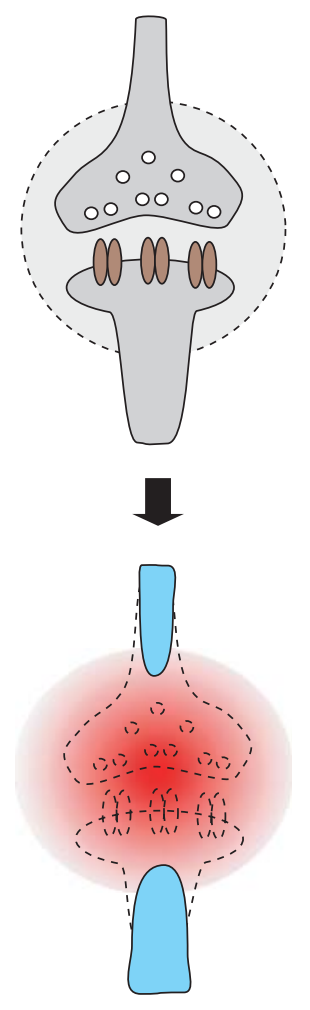

Figure 3. A model for how axon repellents can induce axon repulsion, axon pruning, and synapse elimination. When and where the repellent signaling is activated seem to determine the responses. In the diagram, activated repellent signaling is indicated by red gradient large circles to show the presence of repellent ligands in the environment and by blue axons to show the presence of receptors on the axon terminal or synapse. In contrast, the light and dark gray colors indicate the repellent signaling is not activated yet because of the lack of ligands in the environment or receptors on the axon terminal or synapse. (A) If the repellent signaling is present when the growth cone is navigating through intermediate targets area, the axon is repelled. $(B)$ If the repellent signing is activated only after the axon branch reaches a transient target area, the axon is pruned. (C) Similarly, if the repellent signaling is activated after the transient synapse is formed, the synapse is eliminated as a consequence of the collapse of the axon or dendritic terminal. The presynaptic axon terminal is cartooned with vesicles (small white circles); the postsynaptic dendritic terminal is cartooned with neurotransmitter receptors (brown ovals).

also occurs as a result of cytoskeletal rearrangement near synaptic contacts. In this situation, activated semaphorin signaling induces collapse of pre- and postsynaptic terminal structures and causes subsequent elimination of synapses (Fig. 3C).

\section{Ephrin and Eph}

Stereotyped pruning of the overextended axon branches during retinotopic map formation is regulated by a gradient of signaling by the Ephrin-Eph family of tyrosine kinases. During development, the graded Ephrin-A-EphA signaling along the anterior-posterior axis and the graded Ephrin-B-EphB signaling along the medial-lateral axis control the development of the two-dimensional map (reviewed in Flanagan and Vanderhaeghen 1998; Luo and Flanagan 2007; McLaughlin and O'Leary 2005). It is interesting to note that although Ephrin-BEphB signals bi-directionally to direct retinal 
axon branches to the correct terminal zone along the medial-lateral axis, Ephrin-A-EphA forward signaling inhibits branch formation posterior to the terminal zone and promotes pruning of the overshooting axons. Thus, similarly to semaphorin signaling, the Ephrin-A repulsive signaling is used here to prune stereotypically the overshooting axon branches. However, unlike the retraction mechanism in the IPB pruning, the pruning of the retinal axons could involve degeneration (Nakamura and O'Leary 1989). It also remains unclear whether the overshooting axon branches form transient synapses at incorrect zone.

EphB-Ephrin-B reverse signaling has been implicated in the IPB pruning (Xu and Henkemeyer 2009). Mutant mouse analyses reveal that EphB3 reverse signaling through EphrinB1, Ephrin-B2, and Ephrin-B3 regulate the pruning of the IPB mossy fibers. In vitro experiments further show that EphB stimulation results in Ephrin-B phosphorylation and triggers a signaling pathway involving the Grb4 adaptor. This pathway induces a retraction of the growth cone through a signaling cascade using a guanine nucleotide exchange factor Dock180, a small GTPase Rac, and a downstream effector PAK. There has been no evidence that glial cells are involved in the IPB mossy fiber pruning, but a recent in vitro time-lapse imaging shows that EphB-containing vesicles on the hippocampal neurons are pinched off by neighboring glial cells expressing Ephrin-Bs (Lauterbach and Klein 2006). These results suggest that the EphB/Ephrin-B mediated IPB pruning might be facilitated by glial cells, as has been clearly shown in the small-scale pruning in vertebrates and the pruning in Drosophila (Awasaki and Ito 2004; Bishop et al. 2004; Watts et al. 2004). In addition, it remains to be clarified whether semaphorin signaling involves similar downstream pathways, and how it coordinates with Ephrin-B/EphB reverse signaling to mediate the stereotyped pruning of the IPB.

\section{Other Related Molecules}

Until now, there has been no other axon guidance molecule implicated in the developmental axon pruning in vertebrates. However, a cell death related receptor, death receptor 6 , has been implicated in the stereotyped axon pruning during the retinotopic mapping. This receptor is shown to activate caspase 6 to specifically induce axon degeneration (Nikolaev et al. 2009). In addition, a small-scale pruning of the neurites of a developing interneuron has been described in Caenorhabditis elegans (Kage et al. 2005). This pruning occurs presumably by retraction and is regulated by the transcription factor MBR-1 as well as by extrinsic Wnt ligands (Hayashi et al. 2009). As shown in Figure 3, axon repellents can act as an extrinsic pruning factor in certain context. We can reasonably expect that additional axon repellents such as netrins and slits play a role in developmental pruning. As many of the pruning events described here are associated with neural activity, it will be important to explore if and how activation of, or response to, these extrinsic factors is coupled with neural activity during developmental axon pruning.

\section{NEURAL CELL DEATH AND DEVELOPMENT}

As in most other parts of the developing body (Baehrecke 2002), cell death constitutes an important mechanism contributing to the patterning of the brain (Fig. 4). Two main types of cell death can be distinguished, based on their timing and cellular targets: a late cell death that strikes mainly postmitotic neurons, and an early cell death of dividing progenitors or immature neurons, independently of synaptogenesis (Buss et al. 2006).

These waves of cell death have been described throughout the developing brain, but their relative importance differs from region to region. The underlying molecular and cellular mechanisms also seem to differ, in particular the extrinsic cues and receptors involved, but it is generally admitted that all eventually converge to intracellular pathways controlling classical apoptotic cascades (Bredesen et al. 2006; Yuan et al. 2003). Interestingly, most axon guidance cues, including netrins, semaphorins, and ephrins, have now been shown to be involved in the control of neural cell death, either at the level 
Pruning and Death

A Neuronal death and patterning of neuronal projections
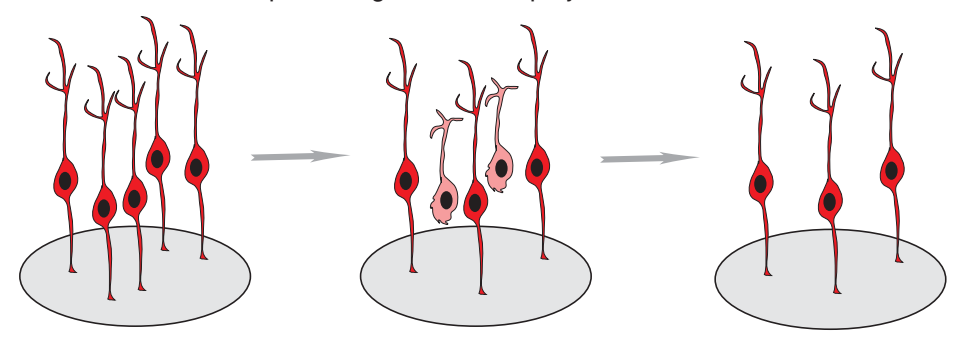

B Neuronal death and axon guidance

Netrin loss of function
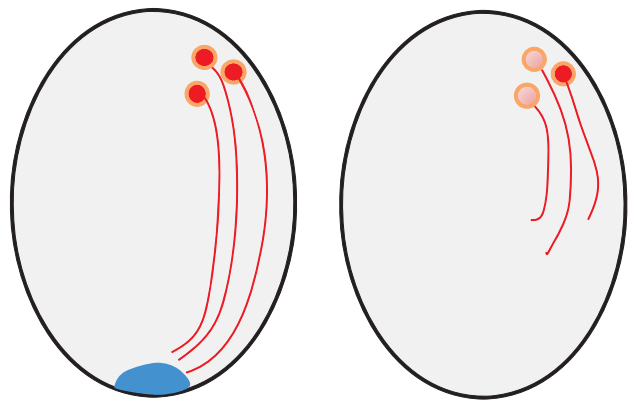

Netrin receptor loss of function

Misguidance and death

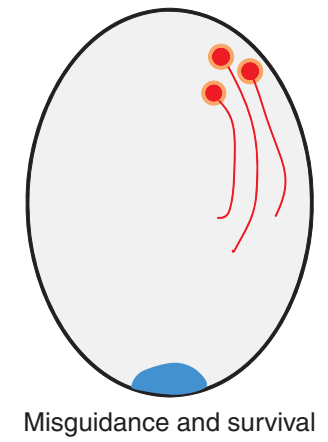

C Neural progenitor death and brain morphogenesis

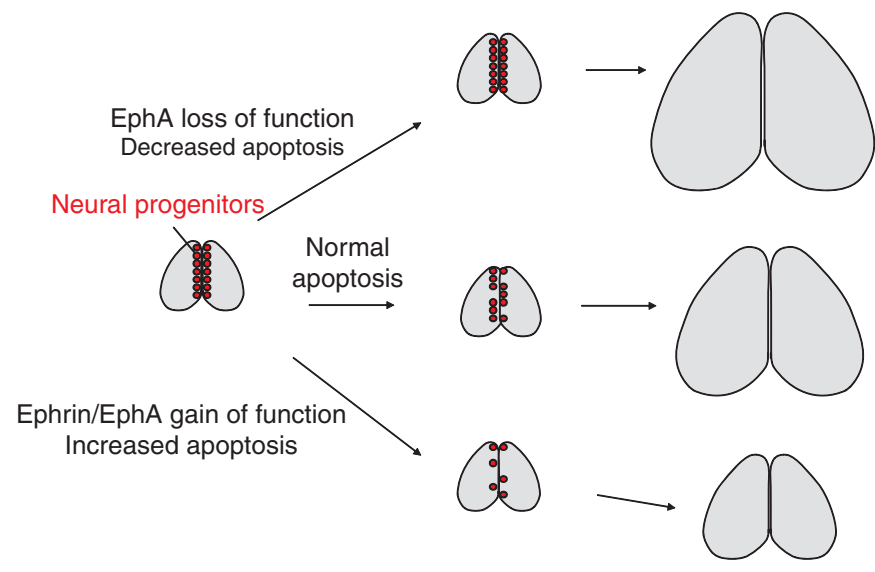

Figure 4. Distinct patterns and mechanisms of neural cell death. (A) According to the neurotrophic model, cell death regulates the final number of neurons that compete for limiting amounts of neurotrophic factors to innervate their target, thereby enabling a precise qualitative and quantitative matching between synaptic partners. (B) A model to link axon guidance and neuronal death. Netrin ligands (in blue) control the guidance and promote the survival of several populations of neurons within the spinal cord and hindbrain. In absence of Netrin, responsive neurons are misguided and display decreased survival. In absence of Netrin receptors, neurons are misguided in a similar way but show normal or sometimes enhanced survival. Overall, these observations are consistent with a dual role of Netrins and their receptors on neuronal guidance and apoptosis. (C) During normal brain development, a subset of neural progenitors undergo apoptosis, which negatively regulates their number. Following ephrin/Eph loss of function, this wave of apoptosis is decreased, which causes an expansion of the progenitor pool, and thereby forebrain overgrowth. Following ephrin/Eph gain of function, the rate of apoptosis of neural progenitors is increased, resulting in a reduction of the pool, and thereby a decrease in forebrain size. 
P. Vanderhaeghen and H.-J. Cheng

of neurons or neural progenitors, aside of their prominent role in neurite patterning.

\section{Neuronal Death and the Neurotrophic Model}

Neuronal death is by far the best described and understood to date, and will not be described in full detail here, given the number of excellent reviews dealing with this classical chapter of developmental neurobiology (Buss et al. 2006; Buss and Oppenheim 2004; Cowan 2001). It has been known for decades that a large proportion of neurons undergo PCD at the time of synaptogenesis. Seminal experiments demonstrating the physiological relevance of these regressing events mainly focused on the development of the peripheral nervous system and of neuromuscular projections. Key findings included the observation that peripheral targets can influence the final number of neurons, essentially through the regulation of neuronal survival. This led to the identification of the first neurotrophic cue, nerve growth factor (NGF), followed by the other neurotrophic factors such as BDNF, GDNF, and NT3-4, which have all been implicated in neuronal survival (Cowan 2001; Huang and Reichardt 2001), and some of which may also act as axon guidance cues (Lumsden and Davies 1986; O’Connor and Tessier-Lavigne 1999; Singh et al. 2008).

According to the neurotrophic hypothesis, neurons compete for access to neurotrophic factors that are released in limiting amounts by their peripheral targets. In this case, the apoptotic cascades are triggered by withdrawal of the factor, which when present control positively pro-survival cascades through their receptors, mainly through a complex retrograde signaling process (Huang and Reichardt 2001; Zweifel et al. 2005).

Neurotrophin withdrawal is thus a major trigger of apoptotic pathways, but pro-apoptotic effects of Neurotrophins or their precursors have also been described, in particular through the p75 receptor (Frade et al. 1996; Raoul et al. 2000). These proapoptotic effects have been proposed to increase the efficacy of the competition process, by enabling to decrease actively the survival or axon outgrowth of neuronal competitors (Deppmann et al. 2008).

The prominent role of neurotrophins in regulating neuronal survival in the peripheral and neuromuscular systems has been widely established in vivo, in particular through the studies centered on mouse mutants for neurotrophins and their receptors, but such analyses have yielded surprisingly few phenotypes related to cell death within the CNS (Buss et al. 2006; Oppenheim et al. 2001). Although these findings have been mainly interpreted as evidence for a high degree of redundancy of neurotrophic genes in the CNS, they also leave open the possibility that additional cues could be involved in specific patterns of neuronal death in these contexts, including axon guidance factors.

Although neuronal death is classically thought to contribute to the qualitative and quantitative matching of presynaptic and postsynaptic partners, in some cases it appears that neurons undergo PCD even before reaching their target (Buss et al. 2006; de la Rosa and de Pablo 2000). This suggests that neuronal death could contribute to other regulatory processes, such as the correction of errors of axonal navigation, which could be particularly relevant in the case of cell death events mediated by some axon guidance molecules. Neuronal death has also been proposed to play a role in sculpting the fine pattern of connectivity in some structures, such as the mapping of retinal projections to the superior colliculus (Buss et al. 2006; Cellerino et al.2000; O'Leary et al. 1986), although from the data available so far, it seems that pruning of axon branches is by far the most prominent regressive event involved in topgraphic mapping.

\section{Early Neural Cell Death and Brain Morphogenesis}

The physiological meaning of apoptosis in neural progenitors has remained largely unexplored for a long time (Bello et al. 2003; Kuan et al. 2000). The presence of significant levels of apoptosis in the proliferative zone of the mouse brain (Blaschke et al. 1996), since then confirmed in other species including the human (Rakic and Zecevic 2000; Yeo and Gautier 2003), suggested that cell death is not a phenomenon exclusively 
restricted to postmitotic neurons, but this did not necessarily imply that apoptosis regulation was linked to brain patterning. A first important hint came from the analysis of caspase gene invalidation in mutant mice: The mutants invalidated for pro-apoptotic genes Caspase-3, Caspase-9, and Apaf1 present a similar phenotype, consisting in a drastic reduction in early cerebral apoptosis and an inappropriate amplification of specific populations of neural progenitors, resulting in brain exencephaly and neural overgrowth (Cecconi et al. 1998; Hakem et al. 1998; Kuida et al. 1996; Kuida et al. 1998; Pompeiano et al. 2000). Most strikingly, the overgrowth is mostly confined to the forebrain, including sometimes an increase in the thickness and surface of the cerebral cortex.

These data support the idea that even modest modifications in the size of the progenitor pool during its exponential growth can directly affect the final size and shape of the mammalian forebrain, which can occur by influencing the proliferation, but also the survival of neural progenitors (Caviness Jr. et al. 1995; Rakic 2005).

Region-specific apoptosis of neural progenitors was also proposed recently as a patterning mechanism to restrict in time and space the size of distinct neural stem cell lineages in Drosophila CNS, thereby playing an essential role in the spatial patterning of the nervous system (Bello et al. 2003).

In vertebrates, the contribution of apoptotic processes to neural regional patterning remains unclear at this stage, although the patterns of neural progenitor apoptosis are strikingly dynamic in time and space (Blaschke et al. 1996; Rakic and Zecevic 2000; Yeo and Gautier 2003). On the other hand, several extracellular cues have been recently identified that control early neural cell death. Intriguingly, most of them turn out to be axon guidance factors as well.

\section{AXON GUIDANCE MOLECULES AND NEURAL CELL DEATH}

\section{Netrins and Their Receptors}

Netrins and their receptors DCC and Unc5 are the first axon guidance actors for which a role in neural cell death was proposed: In vitro data first suggested that overexpression of either DCC or Unc5 could result in increased apoptosis independently of any ligand, although this effect could be largely suppressed by treatment by Netrin ligands (Forcet et al. 2001; Llambi et al. 2001; Mehlen et al. 1998). These observations led to the "dependence receptor" hypothesis, according to which Netrin receptors can function in absence of ligands as pro-apoptotic factors, although this activity is suppressed following ligand binding (Bredesen et al. 2004).

Cell death mediated by DCC and Unc5 has been linked to the cleavage of the intracellular domain of the receptor by caspases, which releases specific proteolytic fragments that mediate the amplification of the apoptotic process (Forcet et al. 2001; Llambi et al. 2001; Mehlen et al. 1998). It has been proposed that dependence receptors thus act mainly as amplifiers of low amounts of caspase activity, which yield to efficient cell death through the release of a part of their intracellular domain that is sufficient to convey death signals. In the case of Unc5 receptors, this intracellular domain bears structural similarities to a death domain structural motif, similar to the one found in p75 and other pro-apoptotic receptors (Frade et al. 1996; Haase et al. 2008; Llambi et al. 2001). Surprisingly, however, the intracellular part of DCC that seems to be necessary and sufficient for apoptotic effects does not bear any homology with such domains.

In vivo data have confirmed a role for Netrin/DCC/Unc5 in the regulation of survival of several neuronal populations of the CNS, in particular in the hindbrain and spinal cord (Fig. 4b) (Bloch-Gallego et al. 1999; Furne et al. 2008; Llambi et al. 2001; Marcos et al. 2009). For instance, in Netrin knock-outs, inferior olivary neurons have been shown to display guidance defects, but also decreased neuronal survival and number (Bloch-Gallego et al. 1999; Marcos et al. 2009). Importantly, although similar guidance defects are observed in DCC mutants, the survival of the neurons appears to be preserved (Marcos et al. 2009). Similarly, the guidance of some of the dorsal spinal cord neurons are affected in Netrin and DCC mutants, 
but Netrin-1 increases, whereas DCC decreases, their survival (Furne et al. 2008). On the other hand, spinal cord neurons display decreased apoptosis in Unc5 loss-of-function mutants (Williams et al. 2006). In other parts of the CNS, Netrin loss-of-function mutants do not seem to display changes in apoptotic rates (Williams et al. 2006), suggesting either redundancy with other DCC/Unc5 ligands, or that these receptors act as dependence cues only in particular cell types or contexts. In any case, the in vivo data obtained so far are consistent with an opposite role for Netrins and their receptors in neuronal survival, which can be clearly distinguished from their role in axonal navigation.

One important pending question in this context concerns the physiological role of Netrin-mediated control of neuronal survival. One possibility is that it acts as an adjuvant signal to neurotrophic factors in mediating competition between presynaptic neurons, but acting largely before the neurons reach their final target. Alternatively, DCC/Unc5-mediated neuronal death could have evolved also as a correction mechanism to remove axons that may have followed wrong pathways, or reached inappropriate targets.

\section{Semaphorins}

The involvement of semaphorins in neural cell death was first suggested by in vitro experiments that identified Sema3A as a death inducing factor for sympathetic neurons (Shirvan et al. 1999) and neural tumor cells (Bagnard et al. 2001). Intriguingly, Sema3A displays differential effects on neurons cultured in the presence of different combinations of neurotrophic factors, suggesting that it could act in combination with them to trigger apoptosis of specific sensory neuron populations (Ben-Zvi et al. 2006). A first in vivo confirmation of these findings was recently provided by the analysis of sensory neurons in Plexin-A3 knockout mice (Ben-Zvi et al. 2008). Disruption of Plexin-A3 results in a decrease in the rate of apoptosis of dorsal root ganglion (DRG) neurons in vivo, particularly at early stages of development. Besides,
Sema3A knockout mice also display a reduction of DRG neuronal apoptosis in a sensitizing genetic background, i.e., in the heterozygotic Bax mutants. The disruption of apoptotic rates was accompanied by an increase in the number of DRG neurons in Plexin-A3 mutants, at least at some levels of the spinal cord, consistent with the hypothesis that semaphorin/plexin signaling can influence neuronal survival and number in vivo. More work is clearly needed to fully assess the physiological relevance of semaphorin-mediated neuronal death within the CNS, including in pathological contexts, especially as semaphorin inhibition has been shown also to reduce the death of retinal ganglion cells following optic nerve axotomy in the adult rat (Shirvan et al. 2002).

\section{Ephrins}

Early reports suggested that ephrin could control cell survival in vitro (Dohn et al. 2001; Yue et al. 1999), but without clear relationship to PCD during neural development.

In vivo demonstration of their implication came from genetic studies in mice (Fig. 4c), focusing on Ephrin-A5 and its receptor EphA7 (Depaepe et al. 2005). In vivo gain of Ephrin-A/EphA function, achieved through ectopic expression of Ephrin-A5 in all cortical progenitors expressing EphA7, causes a transient wave of neural progenitor cell apoptosis, resulting in a premature depletion of progenitors and a subsequent dramatic decrease in cortical size. Conversely, in vivo loss of EphA function, achieved through EphA7 gene disruption, causes a reduction in apoptosis occurring normally in forebrain neural progenitors, resulting in an increase in cortical size and, in extreme cases, exencephalic forebrain overgrowth, strikingly resembling the phenotypes observed in caspase-3, caspase-9, or Apaf1 invalidated mice (Depaepe et al. 2005; Rakic 2005). The spatial and temporal expression pattern of ephrin/Eph genes in the forebrain suggests that ephrin-mediated apoptosis could control not only the cerebral size, but also its regional patterning (Depaepe et al. 2005). In this context it will be interesting to study mouse mutants for 
different ephrin/Eph genes displaying particular regional or temporal patterns of gene expression, and thereby explore the relationships between apoptosis and brain patterning.

More recently, ephrin/Eph cues have been shown to be pro-apoptotic in other cellular contexts (Figueroa et al. 2006; Noren et al. 2006), but also in some cases they seem to act as prosurvival factors, at least in adult mouse neural stem cells (Furne et al. 2009; Ricard et al. 2006). In the latter case, it has been proposed that EphA4 may act as a dependence receptor that would promote cell death in the absence of ephrin ligands, following caspase cleavage processes similar to the ones described for DCC and Unc5 (Furne et al. 2009).

\section{Other Guidance Molecules}

Sonic Hedgehog $(\mathrm{SHH})$ is best known for its role in patterning the vertebrate neural tube, but was also identified as an axon guidance cue for commissural axons (Charron et al. 2003). Its role in the control of neural death was first suggested by embryological experiments showing that removal of the notochord could lead to massive death in the neural tube, which could be rescued by SHH (Charrier et al. 2001). The $\mathrm{SHH}$ receptor Patched was later shown to have an intrinsic pro-apoptotic activity both in vitro and in the chick neural tube, which could be rescued by $\mathrm{SHH}$ stimulation, consistent with a dependence receptor activity (Thibert et al. 2003). More recently, the signaling pathway underlying Patched-mediated apoptosis was shown to involve direct interaction with a proapoptotic complex comprising caspase 9 and the adaptor protein DRAL (Mille et al. 2009). As $\mathrm{SHH}$ and Netrins both have attractant effects on commissural neurons, it will be interesting to test how each cue interacts with the other to coordinate, not only the navigation, but also the survival of similar neuronal populations.

Other factors involved in axonal and dendritic patterning have been involved in the extrinsic regulation of neural cell death, such as lysophosphatidic acid (LPA) (Kingsbury et al. 2003) and CPG15 (Putz et al. 2005), that were found to control cerebral size by promoting the survival of the neural progenitor pool. Repulsive Guidance Molecule (RGM) and its receptor Neogenin were also found to be involved in neural cell death in the chick neural tube, following a mechanism seemingly similar to the Netrin/DCC-dependent system (Matsunaga et al. 2004).

\section{Links Between Axon Guidance and Apoptotic Pathways}

Recent data have pointed to the implication of several apoptosis effectors and regulators in the control of neurite patterning (Campbell and Holt, 2003; Geisbrecht and Montell 2004). Caspase 3 has been shown to be activated at the retinal ganglion axon growth cone following stimulation by several repellent guidance cues such as Netrin 1 and LPA. Caspase 6 on the other hand was recently found to be involved in axon pruning, downstream of the death receptor DR6, following stimulation by APP derived peptides (Nikolaev et al. 2009). Future work should highlight to what extent cell death is the result of acute cytoskeletal disruption, in a way that would be similar to anoikis-related cell death, or whether specific upstream signaling components are actually linking the two processes, depending on the cellular context. More in depth in vivo analyses are also clearly required to assess the physiological role of axon guidance cue-mediated cell death, and to relate it to the better characterized Neurotrophin-dependent systems.

\section{CONCLUSIONS AND FUTURE DIRECTIONS}

Overall, the data reviewed here indicate that most axon guidance cues have evolved the capacity to control neural cell death and axon pruning in addition to their prominent effects on axon guidance. These pleiotropic effects thus bear striking similarity to the multiple roles of classical neurotrophic factors during neural development, which mainly control neuronal survival and neurite outgrowth, but also can act as short-range guidance or pruning factors. 
An important challenge in the field will be to understand how diverse guidance cues seem to be able to control such different aspects of neuronal biology, in such a specific way that is highly dependent on the cellular and developmental contexts. In other words, to what extent do different guidance cues converge to similar intracellular pathways to control cell death and survival, as well as axon guidance and pruning? Another major issue will be to link the findings related to axonal pruning and neural cell death to neural pathologies, which in most cases involves axonal degeneration and neuronal loss.

\section{ACKNOWLEDGMENTS}

We would like to thank Regina Faulkner and Shih-Yu Chen for helping prepare the manuscript. Work from the authors was supported by grants from the National Institutes of Health (HD045757) and March of Dimes Foundation (to H.-J.C.), and from the Belgian FNRS/ FRSM, FMRE, IUAP Programmes, Walloon Excellence Programme Cibles, and the Fondation Clerdent (to P.V.). P.V. is a Senior Researcher of the Belgian FNRS.

\section{REFERENCES}

Adams B, Lee M, Fahnestock M, Racine RJ. 1997. Long-term potentiation trains induce mossy fiber sprouting. Brain Res 775: 193-197.

Amaral DG, Dent JA. 1981. Development of the mossy fibers of the dentate gyrus: I. A light and electron microscopic study of the mossy fibers and their expansions. J Comp Neurol 195: 51-86.

Avery MA, Sheehan AE, Kerr KS, Wang J, Freeman MR. 2009. Wld S requires Nmnatl enzymatic activity and N16-VCP interactions to suppress Wallerian degeneration. J Cell Biol 184: 501-513.

Awasaki T, Ito K. 2004. Engulfing action of glial cells is required for programmed axon pruning during Drosophila metamorphosis. Curr Biol 14: 668-677.

Baehrecke EH. 2002. How death shapes life during development. Nat Rev Mol Cell Biol 3: 779-787.

Bagnard D, Vaillant C, Khuth ST, Dufay N, Lohrum M, Puschel AW, Belin MF, Bolz J, Thomasset N. 2001. Semaphorin 3A-vascular endothelial growth factor-165 balance mediates migration and apoptosis of neural progenitor cells by the recruitment of shared receptor. J Neurosci 21: 3332-3341.
Bagri A, Cheng HJ, Yaron A, Pleasure SJ, Tessier-Lavigne M. 2003. Stereotyped pruning of long hippocampal axon branches triggered by retraction inducers of the semaphorin family. Cell 113: 285-299.

Bello BC, Hirth F, Gould AP. 2003. A pulse of the Drosophila Hox protein Abdominal-A schedules the end of neural proliferation via neuroblast apoptosis. Neuron 37: 209219.

Ben-Zvi A, Manor O, Schachner M, Yaron A, TessierLavigne M, Behar O. 2008. The Semaphorin receptor PlexinA3 mediates neuronal apoptosis during dorsal root ganglia development. J Neurosci 28: 12427-12432.

Ben-Zvi A, Yagil Z, Hagalili Y, Klein H, Lerman O, Behar O. 2006. Semaphorin $3 \mathrm{~A}$ and neurotrophins: a balance between apoptosis and survival signaling in embryonic DRG neurons. J Neurochem 96: 585-597.

Billuart P, Winter CG, Maresh A, Zhao X, Luo L. 2001. Regulating axon branch stability: the role of p190 RhoGAP in repressing a retraction signaling pathway. Cell 107: $195-$ 207.

Bishop DL, Misgeld T, Walsh MK, Gan WB, Lichtman JW. 2004. Axon branch removal at developing synapses by axosome shedding. Neuron 44: 651-661.

Blaschke AJ, Staley K, Chun J. 1996. Widespread programmed cell death in proliferative and postmitotic regions of the fetal cerebral cortex. Development 122: 1165-1174.

Bloch-Gallego E, Ezan F, Tessier-Lavigne M, Sotelo C. 1999. Floor plate and netrin-1 are involved in the migration and survival of inferior olivary neurons. J Neurosci 19: 4407-4420.

Bredesen DE, Mehlen P, Rabizadeh S. 2004. Apoptosis and dependence receptors: a molecular basis for cellular addiction. Physiol Rev 84: 411-430.

Bredesen DE, Rao RV, Mehlen P. 2006. Cell death in the nervous system. Nature 443: 796-802.

Buss RR, Sun W, Oppenheim RW. 2006. Adaptive roles of programmed cell death during nervous system development. Annu Rev Neurosci 29: 1-35.

Campbell DS, Holt CE. 2003. Apoptotic pathway and MAPKs differentially regulate chemotropic responses of retinal growth cones. Neuron 37: 939-952.

Caviness VS Jr, Takahashi T, Nowakowski RS. 1995. Numbers, time and neocortical neuronogenesis: a general developmental and evolutionary model. Trends Neurosci 18: 379-383.

Cecconi F, Alvarez-Bolado G, Meyer BI, Roth KA, Gruss P. 1998. Apaf1 (CED-4 homolog) regulates programmed cell death in mammalian development. Cell 94: 727-737.

Cellerino A, Bahr M, Isenmann S. 2000. Apoptosis in the developing visual system. Cell Tissue Res 301: 53-69.

Charrier JB, Lapointe F, Le Douarin NM, Teillet MA. 2001. Anti-apoptotic role of Sonic hedgehog protein at the early stages of nervous system organogenesis. Development 128: 4011-4020.

Charron F, Stein E, Jeong J, McMahon AP, Tessier-Lavigne M. 2003. The morphogen sonic hedgehog is an axonal chemoattractant that collaborates with netrin-1 in midline axon guidance. Cell 113: 11-23.

Coleman M. 2005. Axon degeneration mechanisms: Commonality amid diversity. Nat Rev Neurosci 6: 889-898. 
Coleman MP, Conforti L, Buckmaster EA, Tarlton A, Ewing RM, Brown MC, Lyon MF, Perry VH. 1998. An 85-kb tandem triplication in the slow Wallerian degeneration (Wlds) mouse. Proc Natl Acad Sci 95: 9985-9990.

Conforti L, Tarlton A, Mack TG, Mi W, Buckmaster EA, Wagner D, Perry VH, Coleman MP. 2000. A Ufd2/ D4Colele chimeric protein and overexpression of Rbp7 in the slow Wallerian degeneration (WldS) mouse. Proc Natl Acad Sci 97: 11377-11382.

Cowan WM. 2001. Viktor Hamburger and Rita LeviMontalcini: the path to the discovery of nerve growth factor. Annu Rev Neurosci 24: 551-600.

Cowan WM, Fawcett JW, O'Leary DD, Stanfield BB. 1984 Regressive events in neurogenesis. Science 225: $1258-$ 1265.

Dehay C, Horsburgh G, Berland M, Killackey H, Kennedy H. 1989. Maturation and connectivity of the visual cortex in monkey is altered by prenatal removal of retinal input. Nature 337: 265-267.

de la Rosa EJ, de Pablo F. 2000. Cell death in early neural development: beyond the neurotrophic theory. Trends Neurosci 23: 454-458.

Depaepe V, Suarez-Gonzalez N, Dufour A, Passante L, Gorski JA, Jones KR, Ledent C, Vanderhaeghen P. 2005. Ephrin signalling controls brain size by regulating apoptosis of neural progenitors. Nature 435: 1244-1250.

Deppmann CD, Mihalas S, Sharma N, Lonze BE, Niebur E, Ginty DD. 2008. A model for neuronal competition during development. Science 320: 369-373.

Dohn M, Jiang J, Chen X. 2001. Receptor tyrosine kinase EphA2 is regulated by p53-family proteins and induces apoptosis. Oncogene 20: 6503-6515.

Eaton BA, Fetter RD, Davis GW. 2002. Dynactin is necessary for synapse stabilization. Neuron 34: 729-741.

Eckenhoff MF, Pysh JJ. 1979. Double-walled coated vesicle formation: evidence for massive and transient conjugate internalization of plasma membranes during cerebellar development. J Neurocytol 8: 623-638.

Faulkner RL, Low LK, Cheng HJ. 2007. Axon pruning in the developing vertebrate hippocampus. Dev Neurosci 29: 6-13.

Figueroa JD, Benton RL, Velazquez I, Torrado AI, Ortiz CM, Hernandez CM, Diaz JJ, Magnuson DS, Whittemore SR, Miranda JD. 2006. Inhibition of EphA7 up-regulation after spinal cord injury reduces apoptosis and promotes locomotor recovery. J Neurosci Res 84: 1438-1451.

Flanagan JG. 2006. Neural map specification by gradients. Curr Opin Neurobiol 16: 59-66.

Flanagan JG, Vanderhaeghen P. 1998. The ephrins and Eph receptors in neural development. Annu Rev Neurosci 21: 309-345.

Forcet C, Ye X, Granger L, Corset V, Shin H, Bredesen DE, Mehlen P. 2001. The dependence receptor DCC (deleted in colorectal cancer) defines an alternative mechanism for caspase activation. Proc Natl Acad Sci 98: 3416-3421.

Frade JM, Rodriguez-Tebar A, Barde YA. 1996. Induction of cell death by endogenous nerve growth factor through its p75 receptor. Nature 383: 166-168.

Furne C, Rama N, Corset V, Chedotal A, Mehlen P. 2008. Netrin-1 is a survival factor during commissural neuron navigation. Proc Natl Acad Sci 105: 14465-14470.
Furne C, Ricard J, Cabrera JR, Pays L, Bethea JR, Mehlen P, Liebl DJ. 2009. EphrinB3 is an anti-apoptotic ligand that inhibits the dependence receptor functions of EphA4 receptors during adult neurogenesis. Biochim Biophys Acta 1793: 231-238.

Geisbrecht ER, Montell DJ. 2004. A role for Drosophila IAP1-mediated caspase inhibition in Rac-dependent cell migration. Cell 118: 111-125.

Haase G, Pettmann B, Raoul C, Henderson CE. 2008. Signaling by death receptors in the nervous system. Curr Opin Neurobiol 18: 284-291.

Hakem R, Hakem A, Duncan GS, Henderson JT, Woo M, Soengas MS, Elia A, de la Pompa JL, Kagi D, Khoo W, et al. 1998. Differential requirement for caspase 9 in apoptotic pathways in vivo. Cell 94: 339-352.

Hashimoto K, Kano M. 2003. Functional differentiation of multiple climbing fiber inputs during synapse elimination in the developing cerebellum. Neuron 38: 785-796.

Hashimoto K, Ichikawa R, Kitamura K, Watanabe M, Kano M. 2009. Translocation of a "winner" climbing fiber to the Purkinje cell dendrite and subsequent elimination of "losers" from the soma in developing cerebellum. Neuron 63: 106-118.

Hayashi Y, Hirotsu T, Iwata R, Kage-Nakadai E, Kunitomo H, Ishihara T, Lino Y, Kubo T. 2009. A trophic role for Wnt-Ror kinase signaling during developmental pruning in Caenorhabditis elegans. Nat Neurosci 12: 981-987.

Haydar TF, Kuan CY, Flavell RA, Rakic P. 1999. The role of cell death in regulating the size and shape of the mammalian forebrain. Cereb Cortex 9: 621-626.

Hoopfer ED, McLaughlin T, Watts RJ, Schuldiner O, O'Leary DD, Luo L. 2006. Wlds protection distinguishes axon degeneration following injury from naturally occurring developmental pruning. Neuron 50: 883-895.

Hoopfer ED, Penton A, Watts RJ, Luo L. 2008. Genomic analysis of Drosophila neuronal remodeling: A role for the RNA-binding protein Boule as a negative regulator of axon pruning. J Neurosci 28: 6092-6103.

Huang EJ, Reichardt LF. 2001. Neurotrophins: Roles in neuronal development and function. Annu Rev Neurosci 24: 677-736.

Innocenti GM. 1981. Growth and reshaping of axons in the establishment of visual callosal connections. Science 212: 824-827.

Innocenti GM, Clarke S. 1984. The organization of immature callosal connections. J Comp Neurol 230: 287-309.

Innocenti GM, Price DJ. 2005. Exuberance in the development of cortical networks. Nat Rev Neurosci 6: 955-965.

Johnston MV. 2004. Clinical disorders of brain plasticity. Brain Dev 26: 73-80.

Kage E, Hayashi Y, Takeuchi H, Hirotsu T, Kunitomo H, Inoue T, Arai H, Iino Y, Kubo T. 2005. MBR-1, a novel helix-turn-helix transcription factor, is required for pruning excessive neurites in Caenorhabditis elegans. Curr Biol 15: 1554-1559.

Kingsbury MA, Rehen SK, Contos JJ, Higgins CM, Chun J. 2003. Non-proliferative effects of lysophosphatidic acid enhance cortical growth and folding. Nat Neurosci 6: 1292-1299. 
P. Vanderhaeghen and H.-J. Cheng

Koralek KA, Killackey HP. 1990. Callosal projections in rat somatosensory cortex are altered by early removal of afferent input. Proc Natl Acad Sci 87: 1396-1400.

Kuida K, Zheng TS, Na S, Kuan C, Yang D, Karasuyama H, Rakic P, Flavell RA. 1996. Decreased apoptosis in the brain and premature lethality in CPP32-deficient mice. Nature 384: 368-372.

Kuida K, Haydar TF, Kuan CY, Gu Y, Taya C, Karasuyama H, Su MS, Rakic P, Flavell RA. 1998. Reduced apoptosis and cytochrome c-mediated caspase activation in mice lacking caspase 9. Cell 94: 325-337.

Kuan CY, Roth KA, Flavell RA, Rakic P. 2000. Mechanisms of programmed cell death in the developing brain. Trends Neurosci 23: 291-297.

Kuo CT, Zhu S, Younger S, Jan LY, Jan YN. 2006. Identification of E2/E3 ubiquitinating enzymes and caspase activity regulating Drosophila sensory neuron dendrite pruning. Neuron 51: 283-290.

Lauterbach J, Klein R. 2006. Release of full-length EphB2 receptors from hippocampal neurons to cocultured glial cells. J Neurosci 26: 11575-11581.

Lee HH, Jan LY, Jan YN. 2009. Drosophila IKK-related kinase Ik2 and Katanin p60-like 1 regulate dendrite pruning of sensory neuron during metamorphosis. Proc Natl Acad Sci 106: 6363-6368.

Lee T, Marticke S, Sung C, Robinow S, Luo L. 2000. Cell-autonomous requirement of the USP/EcR-B ecdysone receptor for mushroom body neuronal remodeling in Drosophila. Neuron 28: 807-818.

Lewis DA, Levitt P. 2002. Schizophrenia as a disorder of neurodevelopment. Annu Rev Neurosci 25: 409-432.

Lichtman JW, Colman H. 2000. Synapse elimination and indelible memory. Neuron 25: 269-278.

Liu XB, Low LK, Jones EG, Cheng HJ. 2005. Stereotyped axon pruning via plexin signaling is associated with synaptic complex elimination in the hippocampus. J Neurosci 25: 9124-9134.

Llambi F, Causeret F, Bloch-Gallego E, Mehlen P. 2001. Netrin-1 acts as a survival factor via its receptors UNC5H and DCC. EMBO J 20: 2715-2722.

Lohof AM, Delhaye-Bouchaud N, Mariani J. 1996. Synapse elimination in the central nervous system: functional significance and cellular mechanisms. Rev Neurosci 7: 85-101.

Low LK, Cheng HJ. 2006. Axon pruning: an essential step underlying the developmental plasticity of neuronal connections. Philos Trans R Soc Lond B Biol Sci 361: 1531- 1544 .

Low LK, Liu XB, Faulkner RL, Coble J, Cheng HJ. 2008. Plexin signaling selectively regulates the stereotyped pruning of corticospinal axons from visual cortex. Proc Natl Acad Sci 105: 8136-8141.

Lumsden AG, Davies AM. 1986. Chemotropic effect of specific target epithelium in the developing mammalian nervous system. Nature 323: 538-539.

Lunn ER, Perry VH, Brown MC, Rosen H, Gordon S. 1989. Absence of Wallerian Degeneration does not Hinder Regeneration in Peripheral Nerve. Eur J Neurosci 1: 2733.

Luo L, Flanagan JG. 2007. Development of continuous and discrete neural maps. Neuron 56: 284-300.
Luo L, O'Leary DD. 2005. Axon retraction and degeneration in development and disease. Annu Rev Neurosci 28: $127-156$.

McLaughlin T, O'Leary DD. 2005. Molecular gradients and development of retinotopic maps. Annu Rev Neurosci 28: 327-355.

Mack TG, Reiner M, Beirowski B, Mi W, Emanuelli M, Wagner D, Thomson D, Gillingwater T, Court F, Conforti L, et al. 2001. Wallerian degeneration of injured axons and synapses is delayed by a Ube4b/Nmnat chimeric gene. Nat Neurosci 4: 1199-1206.

Marcos S, Backer S, Causeret F, Tessier-Lavigne M, BlochGallego E. 2009. Differential roles of Netrin-1 and its receptor DCC in inferior olivary neuron migration. Mol Cell Neurosci 41: 429-439.

Mason CA, Gregory E. 1984. Postnatal maturation of cerebellar mossy and climbing fibers: transient expression of dual features on single axons. J Neurosci 4: 1715-1735.

Matsunaga E, Tauszig-Delamasure S, Monnier PP, Mueller BK, Strittmatter SM, Mehlen P, Chedotal A. 2004. RGM and its receptor neogenin regulate neuronal survival. Nat Cell Biol 6: 749-755.

Mehlen P, Rabizadeh S, Snipas SJ, Assa-Munt N, Salvesen GS, Bredesen DE. 1998. The DCC gene product induces apoptosis by a mechanism requiring receptor proteolysis. Nature 395: 801-804.

Mille F, Thibert C, Fombonne J, Rama N, Guix C, Hayashi H, Corset V, Reed JC, Mehlen P. 2009. The Patched dependence receptor triggers apoptosis through a DRAL-caspase-9 complex. Nat Cell Biol 11: 739-746.

Nakamura H, O’Leary DD. 1989. Inaccuracies in initial growth and arborization of chick retinotectal axons followed by course corrections and axon remodeling to develop topographic order. J Neurosci 9: 3776-3795.

Nikolaev A, McLaughlin T, O’Leary DD, Tessier-Lavigne M. 2009. APP binds DR6 to trigger axon pruning and neuron death via distinct caspases. Nature 457: 981-989.

Noren NK, Foos G, Hauser CA, Pasquale EB. 2006. The EphB4 receptor suppresses breast cancer cell tumorigenicity through an Abl-Crk pathway. Nat Cell Biol 8: 815-825.

O'Connor R, Tessier-Lavigne M. 1999. Identification of maxillary factor, a maxillary process-derived chemoattractant for developing trigeminal sensory axons. Neuron 24: $165-178$.

O'Leary DD. 1987. Remodelling of early axonal projections through the selective elimination of neurons and long axon collaterals. Ciba Found Symp 126: 113-142.

O’Leary DD, Koester SE. 1993. Development of projection neuron types, axon pathways, and patterned connections of the mammalian cortex. Neuron 10: 991-1006.

O'Leary DD, Fawcett JW, Cowan WM. 1986. Topographic targeting errors in the retinocollicular projection and their elimination by selective ganglion cell death. J Neurosci 6: $3692-3705$.

O'Leary DD, Bicknese AR, De Carlos JA, Heffner CD, Koester SE, Kutka LJ, Terashima T. 1990. Target selection by cortical axons: alternative mechanisms to establish axonal connections in the developing brain. Cold Spring Harb Symp Quant Biol 55: 453-468. 
Oppenheim RW, Flavell RA, Vinsant S, Prevette D, Kuan CY, Rakic P. 2001. Programmed cell death of developing mammalian neurons after genetic deletion of caspases. J Neurosci 21: 4752-4760.

Pardo CA, Eberhart CG. 2007. The neurobiology of autism. Brain Pathol 17: 434-447.

Parrish JZ, Emoto K, Kim MD, Jan YN. 2007. Mechanisms that regulate establishment, maintenance, and remodeling of dendritic fields. Annu Rev Neurosci 30: 399-423.

Pompeiano M, Blaschke AJ, Flavell RA, Srinivasan A, Chun J. 2000. Decreased apoptosis in proliferative and postmitotic regions of the Caspase 3-deficient embryonic central nervous system. J Comp Neurol 423: 1-12.

Putz U, Harwell C, Nedivi E. 2005. Soluble CPG15 expressed during early development rescues cortical progenitors from apoptosis. Nat Neurosci 8: 322-331.

Raff MC, Whitmore AV, Finn JT. 2002. Axonal self-destruction and neurodegeneration. Science 296: 868-871.

Rakic P. 2005. Less is more: progenitor death and cortical size. Nat Neurosci 8: 981-982.

Rakic S, Zecevic N. 2000. Programmed cell death in the developing human telencephalon. Eur J Neurosci 12: 2721-2734.

Raoul C, Pettmann B, Henderson CE. 2000. Active killing of neurons during development and following stress: a role for p75(NTR) and Fas? Curr Opin Neurobiol 10: $111-117$.

Reinoso BS, O'Leary DD M. 1989. Extension, branching and regression of visual corticospinal axons in rat. Soc Neurosci Abstr 15: 1337.

Ricard J, Salinas J, Garcia L, Liebl DJ. 2006. EphrinB3 regulates cell proliferation and survival in adult neurogenesis. Mol Cell Neurosci 31: 713-722.

Riley DA. 1981. Ultrastructural evidence for axon retraction during the spontaneous elimination of polyneuronal innervation of the rat soleus muscle. J Neurocytol 10: 425-440.

Sahay A, Molliver ME, Ginty DD, Kolodkin AL. 2003. Semaphorin 3F is critical for development of limbic system circuitry and is required in neurons for selective CNS axon guidance events. J Neurosci 23: 6671-6680.

Sanes JR, Lichtman JW. 1999. Development of the vertebrate neuromuscular junction. Annu Rev Neurosci 22: 389-442.

Sanes JR, Lichtman JW. 2001. Induction, assembly, maturation and maintenance of a postsynaptic apparatus. Nat Rev Neurosci 2: 791-805.

Schuldiner O, Berdnik D, Levy JM, Wu JS, Luginbuhl D, Gontang AC, Luo L. 2008. piggyBac-based mosaic screen identifies a postmitotic function for cohesin in regulating developmental axon pruning. Dev Cell 14: 227-238.

Shatz CJ. 1977. Anatomy of interhemispheric connections in the visual system of Boston Siamese and ordinary cats. J Comp Neurol 173: 497-518.

Shirvan A, Kimron M, Holdengreber V, Ziv I, Ben-Shaul Y, Melamed S, Melamed E, Barzilai A, Solomon AS. 2002. Anti-semaphorin 3A antibodies rescue retinal ganglion cells from cell death following optic nerve axotomy. J Biol Chem 277: 49799-49807.
Shirvan A, Ziv I, Fleminger G, Shina R, He Z, Brudo I, Melamed E, Barzilai A. 1999. Semaphorins as mediators of neuronal apoptosis. J Neurochem 73: 961-971.

Singh KK, Park KJ, Hong EJ, Kramer BM, Greenberg ME, Kaplan DR, Miller FD. 2008. Developmental axon pruning mediated by BDNF-p75NTR-dependent axon degeneration. Nat Neurosci 11: 649-658.

Song JW, Misgeld T, Kang H, Knecht S, Lu J, Cao Y, Cotman SL, Bishop DL, Lichtman JW. 2008. Lysosomal activity associated with developmental axon pruning. J Neurosci 28: 8993-9001.

Stanfield BB. 1992. The development of the corticospinal projection. Prog Neurobiol 38: 169-202.

Stanfield BB, O'Leary DD, Fricks C. 1982. Selective collateral elimination in early postnatal development restricts cortical distribution of rat pyramidal tract neurones. Nature 298: $371-373$.

Tessier CR, Broadie K. 2008. Drosophila fragile X mental retardation protein developmentally regulates activitydependent axon pruning. Development 135: 1547-1557.

Thibert C, Teillet MA, Lapointe F, Mazelin L, Le Douarin NM, Mehlen P. 2003. Inhibition of neuroepithelial patched-induced apoptosis by sonic hedgehog. Science 301: $843-846$.

Truman JW. 1990. Metamorphosis of the central nervous system of Drosophila. J Neurobiol 21: 1072-1084.

Waimey KE, Cheng HJ. 2006. Axon pruning and synaptic development: how are they per-plexin? Neuroscientist 12: $398-409$.

Watts RJ, Hoopfer ED, Luo L. 2003. Axon pruning during Drosophila metamorphosis: evidence for local degeneration and requirement of the ubiquitin-proteasome system. Neuron 38: 871-885.

Watts RJ, Schuldiner O, Perrino J, Larsen C, Luo L. 2004. Glia engulf degenerating axons during developmental axon pruning. Curr Biol 14: 678-684.

Weimann JM, Zhang YA, Levin ME, Devine WP, Brulet P, McConnell SK. 1999. Cortical neurons require Otxl for the refinement of exuberant axonal projections to subcortical targets. Neuron 24: 819-831.

Williams DW, Kondo S, Krzyzanowska A, Hiromi Y, Truman JW. 2006. Local caspase activity directs engulfment of dendrites during pruning. Nat Neurosci 9: 1234-1236.

Williams ME, Lu X, McKenna WL, Washington R, Boyette A, Strickland P, Dillon A, Kaprielian Z, Tessier-Lavigne M, Hinck L. 2006. UNC5A promotes neuronal apoptosis during spinal cord development independent of netrin-1. Nat Neurosci 9: 996-998.

Xu NJ, Henkemeyer M. 2009. Ephrin-B3 reverse signaling through Grb4 and cytoskeletal regulators mediates axon pruning. Nat Neurosci 12: 268-276.

Yeo W, Gautier J. 2003. A role for programmed cell death during early neurogenesis in xenopus. Dev Biol 260: 31-45.

Yoshida H, Kong YY, Yoshida R, Elia AJ, Hakem A, Hakem R, Penninger JM, Mak TW. 1998. Apaf1 is required for mitochondrial pathways of apoptosis and brain development. Cell 94: 739-750. 
P. Vanderhaeghen and H.-J. Cheng

Yuan J, Lipinski M, Degterev A. 2003. Diversity in the mechanisms of neuronal cell death. Neuron 40: 401413.

Yue Y, Su J, Cerretti DP, Fox GM, Jing S, Zhou R. 1999. Selective inhibition of spinal cord neurite outgrowth and cell survival by the Eph family ligand ephrin-A5. J Neurosci 19: $10026-10035$.
Zhai Q, Wang J, Kim A, Liu Q, Watts R, Hoopfer E, Mitchison T, Luo L, He Z. 2003. Involvement of the ubiquitin-proteasome system in the early stages of wallerian degeneration. Neuron 39: 217-225.

Zweifel LS, Kuruvilla R, Ginty DD. 2005. Functions and mechanisms of retrograde neurotrophin signalling. Nat Rev Neurosci 6: 615-625. 


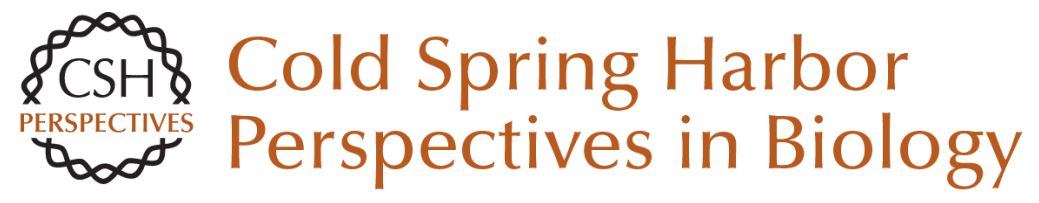

\section{Guidance Molecules in Axon Pruning and Cell Death}

Pierre Vanderhaeghen and Hwai-Jong Cheng

Cold Spring Harb Perspect Biol 2010; doi: 10.1101/cshperspect.a001859 originally published online April 21, 2010

\section{Subject Collection Neuronal Guidance}

Mechanisms and Molecules of Neuronal Wiring: A Primer

Alex L. Kolodkin and Marc Tessier-Lavigne

Guidance Molecules in Axon Pruning and Cell

Death

Pierre Vanderhaeghen and Hwai-Jong Cheng

Initiating and Growing an Axon

F. Polleux and William Snider

Navigating Intermediate Targets: The Nervous System Midline

Barry J. Dickson and Yimin Zou

Cellular Strategies of Axonal Pathfinding

Jonathan Raper and Carol Mason

Guidance Molecules in Axon Regeneration

Roman J. Giger, Edmund R. Hollis II and Mark H. Tuszynski

Signaling from Axon Guidance Receptors Greg J. Bashaw and Rüdiger Klein

Visual Map Development: Bidirectional Signaling, Bifunctional Guidance Molecules, and

Competition

David A. Feldheim and Dennis D. M. O'Leary
Wiring the Brain: The Biology of Neuronal

Guidance

Alain Chédotal and Linda J. Richards

Guidance Molecules in Synapse Formation and

Plasticity Kang Shen and Christopher W. Cowan

The Growth Cone Cytoskeleton in Axon

Outgrowth and Guidance

Erik W. Dent, Stephanie L. Gupton and Frank B. Gertler

Topographic Mapping--The Olfactory System Takeshi Imai, Hitoshi Sakano and Leslie B. Vosshall

Self-avoidance and Tiling: Mechanisms of

Dendrite and Axon Spacing Wesley B. Grueber and Alvaro Sagasti

Trafficking Guidance Receptors Bettina Winckler and Ira Mellman

Axon Guidance Molecules in Vascular Patterning Ralf $H$. Adams and Anne Eichmann

Human Genetic Disorders of Axon Guidance Elizabeth C. Engle

For additional articles in this collection, see http://cshperspectives.cshlp.org/cgi/collection/

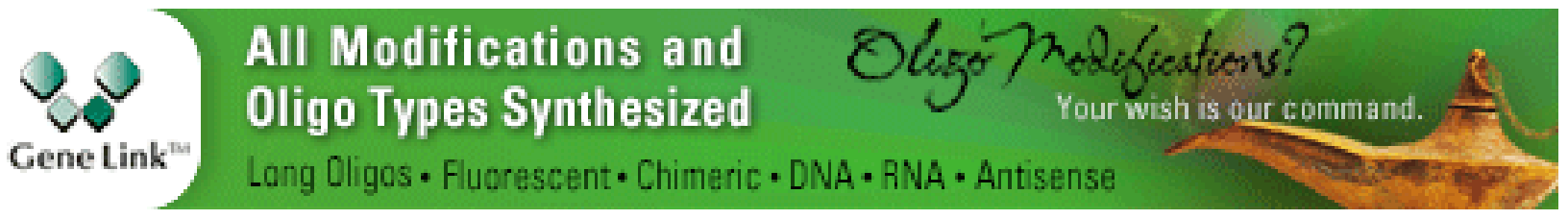

Copyright @ 2010 Cold Spring Harbor Laboratory Press; all rights reserved 